\title{
Thermal stability and decomposition of diesel fuel under subcritical and
}

\section{supercritical conditions}

\author{
Ronghong Lin and Lawrence L. Tavlarides * \\ Department of Biomedical and Chemical Engineering, Syracuse University, \\ 121 Link Hall, Syracuse, NY 13244, USA \\ * Corresponding author. Tel.: +1 315443 1883; Fax: +1 3154439175. \\ E-mail addresses: 1ltavlar@syr.edu (Tavlarides), rlin01@syr.edu (Lin).
}

Citation to this paper:

R. Lin and L. L. Tavlarides, Thermal stability and decomposition of diesel fuel under subcritical and supercritical conditions, Journal of Supercritical Fluids, 75, 101-111, 2013.

\begin{abstract}
A novel concept of clean diesel combustion using supercritical fluids is proposed and being investigated to address some key challenges encountered in the fuel and transportation sector. The core of this concept is to inject diesel fuel (DF) in the supercritical state to achieve clean, highefficient combustion in diesel engines. Among other challenging issues that must be addressed for the implementation of this new concept is the thermal stability of DF and the potential decomposition and solid deposit formation under engine conditions. In this work, thermal stability of DF was experimentally evaluated under subcritical and supercritical conditions in both static (batch system) and dynamic (continuous flow system) thermal stressing systems. The effects of thermal stressing temperature $\left(200-440{ }^{\circ} \mathrm{C}\right)$ and duration $(10-600 \mathrm{~min})$ and $\mathrm{CO}_{2}$ concentration $(\sim 10$ wt\%) were examined. DF decomposition is characterized by the average absolute deviation (AAD) of GC peak area percentages of all individual components. A temperature-time window (400-420
\end{abstract}


${ }^{\circ} \mathrm{C}$, 0-60 min) where supercritical DF combustion in diesel engines may be possible was determined. $\mathrm{CO}_{2}$ as a diluent could prevent or reduce accumulation of solid deposits inside fuel pipes mainly due to an increased solubilization capacity of DF. Finally, different structures and morphologies of solid deposits observed under different batch thermal stressing conditions were discussed.

Keywords: Decomposition, Diesel fuel, solid deposits, supercritical, thermal stability.

\section{Introduction}

Motivated by the increasing demands for transportation fuels and the more stringent emission regulations, a novel concept of clean diesel combustion using supercritical fluids is proposed and being investigated [1-3]. The core of this new concept is to inject diesel fuel (DF) in the supercritical state instead of in the liquid state. Elimination of the droplet vaporization process would enhance fuel-air mixing and consequently, improve energy efficiency and reduce harmful emissions. To develop this new internal combustion engine technology, the thermal stability and possible decomposition of DF under extreme thermal conditions has to be addressed, among other key issues. DF would undergo extreme thermal stress for the time durations to reach the supercritical state before injection during engine operation and to cool down during the engine shutdown period. Previous studies have demonstrated severe engine failures caused by fuel coking at high temperatures [4]. Therefore, the science-based process design and development requires a better understanding of DF stability at high temperatures.

The thermal stability of DF at relatively high temperatures has been minimally explored. Except for a few papers discussing DF stability below $150{ }^{\circ} \mathrm{C}$ [5-9], only three papers were found discussing thermal stability of DF at relatively high temperatures [10-12]. Nickolaus and Lefebvre [10] studied fuel injection at $317^{\circ} \mathrm{C}$ and observed an increase in pressure drop across the nozzle due 
to deposit formation. Beal and Hardy [11] studied thermal stability of DF using a quantitative gravimetric jet fuel thermal oxidation tester and found that thermal stressing of $\mathrm{DF}$ at $260{ }^{\circ} \mathrm{C}$ and 3.4 $\mathrm{MPa}$ for a residence time of $6 \mathrm{~s}$ and for an experimental duration of $2.5 \mathrm{~h}$ resulted in significant formation of solid deposits. Anitescu et al. [12] studied thermal behavior of DF-diluent mixtures at temperatures and pressures up to $477{ }^{\circ} \mathrm{C}$ and $60 \mathrm{MPa}$, respectively, and concluded that fuel decompositions could be reduced with the addition of diluents. These previous investigations suggest that DF starts to degrade at about $260{ }^{\circ} \mathrm{C}$ and the degradation leads to the formation of solid deposits (or fuel coking) and diluents such as $\mathrm{CO}_{2}$ may be able to reduce fuel decomposition and coking.

Thermal stability of a fuel is defined as the capability of the fuel to withstand high temperature stress for a reasonable time period without noticeable deterioration [13]. Such deterioration may include color change, formation of solid deposits, changes in physical properties, chemical properties and combustion properties, etc. Although thermal stability of DF has been minimally explored, extensive research on jet fuel stability has provided major variables that affect and control fuel decomposition and solid deposit formation. These variables fall into two categories: (1) chemical variables (or fuel-related variables) including fuel type, fuel processing, fuel composition, oxygen/sulfur/nitrogen contents and fuel additives, and (2) physical variables (or operating variables) including temperature, pressure, heat flux, flow regime, test duration and heated wall characteristics [3]. Studies on jet fuel thermal stability have been very beneficial to the understanding of DF thermal stability; for example, it has been suggested that the mechanisms of thermal-oxidation-reaction-induced deposit formation for DF and jet fuels are mechanistically similar [14]. In addition, it has been reported that thermal decomposition of liquid hydrocarbon fuels (jet fuel, DF, etc.) falls into three different regimes [15]:

Thermal oxidation reaction regime $\left(<300^{\circ} \mathrm{C}\right)$ : Decomposition occurs by autoxidation reactions and 
increases with increasing fuel temperature. The temperature range of this regime largely depends on fuel properties, and it has been reported that deposition began at $260{ }^{\circ} \mathrm{C}$ and became worse at 325 $400{ }^{\circ} \mathrm{C}[16]$.

Transition regime $\left(300-500{ }^{\circ} \mathrm{C}\right)$ : Both autoxidation and pyrolysis reactions contribute to decomposition and the rate of decomposition decreases with increase in fuel temperature possibly due to the transition from the liquid phase to the supercritical phase which enhanced solvent capability [17] or due to depletion of hydroperoxides [16].

Pyrolysis reaction regime $\left(>500{ }^{\circ} \mathrm{C}\right)$ : Direct pyrolysis dominates and decomposition is enhanced as fuel temperature increases.

As part of the ongoing efforts to develop supercritical fuel combustion technology [1-3,1821], this work is intended to provide a scientific base for the design of high temperature DF delivery and combustion systems. The major objectives are to provide a better understanding of thermal stability and decomposition behavior of DF under subcritical and supercritical conditions, to demonstrate the effects of thermal stressing temperature and duration and $\mathrm{CO}_{2}$ as a diluent on DF decomposition, and more importantly, to determine a thermal stressing temperature-time window where the operation of supercritical fuel injection in internal combustion engines would be practical. $\mathrm{CO}_{2}$ is chosen as a surrogate for the diesel engine exhaust gas to simplify our experiments. The exhaust gas was originally proposed to be recycled to the fuel system for two reasons - recover energy and reduce fuel decomposition [1]. It is recognized that the addition of a diluent (either $\mathrm{CO} 2$ or real exhaust gas) to DF will reduce the energy density of the fuel in diesel engines. To address the impacts on engine performance of a diluent, engine experiments are required that are beyond the scope of this work.

Both static and dynamic thermal stressing experiments were conducted for no. $2 \mathrm{DF}$ and $\mathrm{DF} / \mathrm{CO}_{2}$ mixtures. Fuel samples were then analyzed using gas chromatography equipped with a 
mass selective detector (GC-MSD). Solid deposits were observed with a scanning electron microscope (SEM). Results from both the static and the dynamic experiments are valuable and significant for the intended application in supercritical DF delivery and combustion in diesel engines because diesel engines undergo both static (during shutdown period) and dynamic (under running conditions) operational conditions.

\section{Experimental}

\subsection{Materials}

The DF used in this work was no.2 DF purchased from a local gas station, and the measured density was $0.835 \pm 0.004 \mathrm{~g} / \mathrm{ml}$ at room temperature. Hexane (pesticide grade) was purchased from Fisher Scientific, and carbon dioxide (bone dry) was supplied by Airgas.

\subsection{Batch thermal stressing of DF}

Batch thermal stressing of DF was carried out in a stainless steel tee (Fig. 1B, internal volume: ca. $0.6 \mathrm{ml}$ ) using a gas chromatograph oven (HP 5890) as a heating source. A schematic diagram of the setup is shown in Fig. 1A. DF of $0.45 \mathrm{ml}$ was manually loaded in a $\mathrm{CO}_{2}$ environment to avoid the trapping of air because oxygen affects fuel stability [17,22-25]. The oven temperature $\left(T_{1}\right)$ and the fuel temperature $\left(T_{2}\right)$ were measured by two thermocouples and recorded by a data acquisition system (LabVIEW, National Instruments). A small piece of stainless steel sheet (Fig. 1C) was added into the tee in each run to capture potential solid deposits formed during the thermal stressing process. Experiments were conducted at $200-440{ }^{\circ} \mathrm{C}$ for varying isothermal durations from $10 \mathrm{~min}$ to $600 \mathrm{~min}$ (Table 1, run \#1-17). The maximum thermal stressing temperature was limited to $440{ }^{\circ} \mathrm{C}$ because a preliminary run showed that DF decomposed at $440{ }^{\circ} \mathrm{C}$ for a thermal stressing duration of $10 \mathrm{~min}$. 


\subsection{Batch thermal stressing of $\mathrm{DF} / \mathrm{CO}_{2}$ mixtures}

Batch thermal stressing of $\mathrm{DF} / \mathrm{CO}_{2}$ mixtures and $\mathrm{DF}$ for comparison was carried out in a stainless steel cross (internal volume: ca. $2 \mathrm{ml}$ ) heated by a heating tape (Briskheat). As illustrated in Fig. 1D, one opening of the cross was connected to a double-piston pump and two syringe pumps for the delivery of DF (Dynamex, Model SD-1), $\mathrm{CO}_{2}$ (ISCO 260D) and hexane (ISCO 100D), respectively, and the other three openings were connected to a pressure transducer $(\mathrm{P})$, a thermocouple $\left(\mathrm{T}_{2}\right)$ and a waste collection vial, respectively. Fuel temperature $\left(\mathrm{T}_{2}\right)$, fuel pressure $(\mathrm{P})$, and heating temperature $\left(\mathrm{T}_{1}\right)$ were monitored and recorded by the data acquisition system. Experimental conditions are shown in Table 1 (run \# 18-22). For thermal stressing of $\mathrm{DF} / \mathrm{CO}_{2}$ mixtures, a known amount of DF was pumped into the cross first, and then the cross was filled with $\mathrm{CO}_{2}$ to $4.83 \mathrm{MPa}$ at room temperature. After each run, the cross was rinsed with hexane and then supercritical $\mathrm{CO}_{2}$ for the next run. In the last run (run \#22) of this set of experiments, the $\mathrm{DF} / \mathrm{CO}_{2}$ mixture was heated continuously at $\sim 15{ }^{\circ} \mathrm{C} / \mathrm{min}$ up to $600{ }^{\circ} \mathrm{C}$ to study the starting point of significant DF decomposition. The $T-P$ history was recorded, but fuel was coked and no sample was collected for analysis.

\subsection{Continuous flow thermal stressing experiments}

To eliminate the possible effect of pressure on fuel decomposition, isobaric continuous flow thermal stressing experiments were conducted. As schematically illustrated in Fig. 1E, the flow system was mainly composed of a double-piston pump (Dynamex, Model SD-1) and a syringe pump (ISO 260D) used for pumping DF and $\mathrm{CO}_{2}$, respectively, a heating tape to preheat fuel mixtures, a thermal stressing stainless steel coil (I.D. $1.524 \mathrm{~mm}, 18.3 \mathrm{~m}$ ) located in a GC oven, a cooling coil placed in a water bath, a stainless steel micro-filter (4200 series, Norman Filter) to 
capture potential solid deposits, a back pressure regulator (Swagelok), thermocouples $\left(\mathrm{T}_{1}-\mathrm{T}_{4}\right)$, pressure transducers $\left(\mathrm{P}_{1}, \mathrm{P}_{2}\right)$, and a data acquisition system. Thermal stressing of $\mathrm{DF} / \mathrm{CO}_{2}$ mixtures (DF: $\mathrm{CO}_{2}=9: 1$ by mass) and DF for comparison was conducted at $440{ }^{\circ} \mathrm{C}$ and $30 \mathrm{MPa}$ for a residence time 30 min (Table 1, run \#22-23). The $\mathrm{DF} / \mathrm{CO}_{2}$ mass ratio was selected to reduce the critical temperature of the fuel mixture to a value for which diesel fuel decomposition was minimal and the energy density of the fuel was not reduced significantly. The approach to determine the estimate is discussed in section 3.1. Each run lasted about 13 hours, and samples were collected in one hour intervals.

\subsection{Fuel analysis by GC-MSD}

DF compositions were analyzed by GC-MSD (HP 5890, HP 5971) equipped with a HP-1MS crosslinked methyl siloxane column $(30 \mathrm{~m} \times 0.25 \mathrm{~mm} \times 0.25 \mu \mathrm{m})$. The oven temperature program was: hold at $45{ }^{\circ} \mathrm{C}$ for $3 \mathrm{~min}$, ramp $1{ }^{\circ} \mathrm{C} / \mathrm{min}$ to $270{ }^{\circ} \mathrm{C}$ and hold for $4 \mathrm{~min}$. The injector and detector temperatures were $260{ }^{\circ} \mathrm{C}$ and $285{ }^{\circ} \mathrm{C}$, respectively. All samples were prepared by diluting $2.0 \mu \mathrm{l}$ DF in $1.0 \mathrm{ml}$ hexane, and the injection volume was $1.0 \mu 1$.

Fig. 2 shows examples of chromatograms for fresh DF and DF thermally stressed at $440{ }^{\circ} \mathrm{C}$ for $120 \mathrm{~min}$. The No. $2 \mathrm{DF}$ used in this study is composed of a variety of hydrocarbons having carbon numbers mainly from 8 to 25 (Fig. 2A). Thermal decomposition of DF involves both pyrolysis of high molecular weight compounds having carbon numbers mainly of 15 and above (Fig. 2B) and formation of poly aromatic hydrocarbons via polymerization reactions. For quantitative analysis of fuel decomposition, a new method is proposed below. Chromatograms are integrated and area percentages of individual peaks $(A \%)$ are calculated. The deviations of $A \%$ for all DF components after thermal stressing can then be calculated by 


$$
\Delta(A \%)_{i}=\left(A_{i, T S} / \sum_{j=1}^{n} A_{j, T S}-A_{i, F} / \sum_{j=1}^{n} A_{j, F}\right) \times 100
$$

where subscripts $T S$ and $F$ denote thermally-stressed DF and fresh DF, respectively, subscripts $i$ and $j$ denote the $i^{\text {th }}$ and $j^{\text {th }}$ peaks, respectively, and $n$ denotes the total number of peaks. A negative $\Delta(A \%)_{i}$ value means thermal decomposition of the $i^{\text {th }}$ compound, while a positive $\Delta(A \%)_{i}$ value indicates production of the $i^{\text {th }}$ compound due to decomposition of other DF components. Since both negative and positive $\Delta(A \%)_{i}$ values indicate DF decomposition, the average absolute deviation $(A A D)$ of $A \%$ given by Eq. (2) is used to characterize DF decomposition, and the greater $A A D$ value means the higher degree of fuel decomposition.

$$
A A D \%=\frac{1}{n} \times \sum_{i=1}^{n}\left|\Delta(A \%)_{i}\right|
$$

Theoretically, the $A A D$ value would be zero if no decomposition occurs. However, a $\triangle(A \%)$ plot for fresh DF (Fig. 2C) shows small analytical uncertainty $(A A D=0.06 \%)$, and the average $A A D$ value for three fresh DF samples was $(0.07 \pm 0.01) \%$. Therefore, DF is considered thermally stable if the $A A D$ value for thermally-stressed DF is within the analytical uncertainty. Fig. 2D shows an $A A D$ value of $0.34 \%$ for DF thermally stressed at $440{ }^{\circ} \mathrm{C}$ for $120 \mathrm{~min}$ and indicates a significant decomposition.

In additional to $A A D$ values, we also calculated mean $\mathrm{GC}$ retention time by

$$
\bar{\tau}=\sum_{i=1}^{n}\left(\tau_{i} A_{i}\right) / \sum_{i=1}^{n} A_{i}
$$

where $\tau_{i}$ and $A_{i}$ are the GC retention time and the peak area for peak $i$, respectively. A lower $\bar{\tau}$ would imply that the pyrolysis reactions are more significant than the polymerization reactions, and vice versa, but a constant $\bar{\tau}$ does not necessarily mean that DF is stable. Despite this limitation, it would provide additional information to the fuel decomposition analysis. 


\subsection{Solid deposit characterization by SEM}

Solid deposits formed on stainless steel sheets during the thermal stressing process were characterized by SEM (JEOL, JSM-5600). Samples were rinsed with hexane and then dried in air at room temperature before SEM observation.

\section{Results and Discussion}

\subsection{Critical points of $\mathrm{DF}$ and $\mathrm{DF} / \mathrm{CO}_{2}$ mixtures}

This work is focusing on fuel stability and decomposition under both subcritical and supercritical conditions, so we first studied the critical points of $\mathrm{DF}$ and $\mathrm{DF} / \mathrm{CO}_{2}$ mixtures. The critical point of real DF can be estimated using empirical correlations, and we have reported in a previous study the critical point of $\mathrm{DF}$, which is $\left(440-470{ }^{\circ} \mathrm{C}, 1.9-2.2 \mathrm{MPa}\right)$ and largely dependent of DF distillation profiles [20]. Estimating the critical points of $\mathrm{DF} / \mathrm{CO}_{2}$ mixtures is extremely challenging due to the complexity of DF chemical compositions and the limitations of current modeling techniques. Therefore, we choose n-hexadecane as a surrogate for DF and calculate the critical points of $\mathrm{n}$-hexadecane/ $\mathrm{CO}_{2}$ mixtures. $\mathrm{n}$-Hexadecane is chosen because it is a major component of DF and has a critical point close to that of real DF [20]. This simulation would provide relatively reliable estimates for the critical points of $\mathrm{DF} / \mathrm{CO}_{2}$ mixtures.

The critical points of $n$-hexadecane/ $\mathrm{CO}_{2}$ mixtures of varying compositions were estimated by solving the Soave-Redlich-Kwong equation of state [26] using the $\mathrm{PRO} / \mathrm{II}^{\circledR}$ process engineering software (Invensys Inc.). Results are presented in Fig. 3, along with literature data [27,28]. Also plotted in Fig. 3 is the critical point range of real DF [20]. It is found that the critical temperature of the $\mathrm{n}$-hexadecane/ $\mathrm{CO}_{2}$ mixture decreases and the critical pressure increases as the n-hexadecane molar fraction $\left(\mathrm{X}_{\mathrm{HD}}\right)$ decreases (or the $\mathrm{CO}_{2}$ molar fraction increases). This result is important 
because it indicates the possibility to transfer fuels from the liquid state to the supercritical state at relatively lower temperatures by adding diluents or additives.

\subsection{Coupled effects of temperature and residence time on DF thermal stability}

In the first set of batch experiments, DF was thermally stressed at $200-440{ }^{\circ} \mathrm{C}$ for $10-600$ min. Selected photos of DF samples are presented in Fig. 4, from which thermal stability behavior is roughly observed. At $300{ }^{\circ} \mathrm{C}$, DF was very stable and noticeable color changes were only observed after 600 -min thermal stressing. This observation is contradictory to the previous study where DF was found to start to degrade at $260{ }^{\circ} \mathrm{C}$ [11]. The possible explanations are the different experimental techniques used in the two studies and the improvement of fuel quality over the past two decades. In the former case, instead of analyzing the fuel they analyzed surface depositions on a metal foil strip resulting from flowing heated fuel at $260 \mathrm{oC}$ over the strip for 2.5 hours. As temperature increased to $400{ }^{\circ} \mathrm{C}$, DF still showed good stability for residence times up to $180 \mathrm{~min}$. The fuel stability significantly reduced as temperature increased to $420{ }^{\circ} \mathrm{C}$ and further to $440{ }^{\circ} \mathrm{C}$. Fuel color started to change at about $30 \mathrm{~min}$ and $10 \mathrm{~min}$ for $420{ }^{\circ} \mathrm{C}$ and $440{ }^{\circ} \mathrm{C}$, respectively. The red curve in Fig. 4 indicates a rough transition zone, above which DF is unstable and below which it is stable. This curve also implies that DF could withstand higher temperatures if the residence time were much shorter, and this deduction is confirmed by the observation made in run \#22 in Table 1 and presented in Fig. 5. In run $\# 22$, the $\mathrm{DF} / \mathrm{CO}_{2}$ mixture was heated at $\sim 15{ }^{\circ} \mathrm{C} / \mathrm{min}$ from room temperature to $440{ }^{\circ} \mathrm{C}$ and then cooled down to room temperature. The overlapping of the heating and cooling curves indicates negligible DF decomposition. The fuel mixture was re-heated at the same heating rate to more than $600{ }^{\circ} \mathrm{C}$, and a sharp increase in pressure was observed in the $P-T$ curve at about $470{ }^{\circ} \mathrm{C}$ (Fig. 5). The sharp change in the slope of the $P$ - $T$ curve corresponds to the onset of significant DF decomposition. Since the time duration from 440 to $470{ }^{\circ} \mathrm{C}$ was about $2 \mathrm{~min}$, 
we may conclude that DF can withstand high thermal stress under near critical or supercritical conditions for reasonable time durations $(<2 \mathrm{~min})$. These time durations would be comparable with those required for DF to reach the supercritical state before injection during engine operation. However, DF would undergo the extreme thermal stress for longer time durations to cool down during the engine shutdown period, depending on the efficiency of cooling systems. Therefore, the current study is focused on DF thermal stability at temperatures up to $440{ }^{\circ} \mathrm{C}$ for longer thermal stressing durations.

Quantitative stability and decomposition information can be obtained from the $A A D$ plot presented in Fig. 6, in which the solid straight line represents the average $A A D$ value for fresh DF and the dash straight lines represent the standard deviation. When thermal stressing temperatures were less than $420{ }^{\circ} \mathrm{C}$ and the residence time was no greater than $60 \mathrm{~min}$, the $A A D$ values were within the range of analytical uncertainties, indicating the good stability of DF under these thermal stressing conditions. At $300{ }^{\circ} \mathrm{C}$ and $600 \mathrm{~min}$, the $A A D$ increased to $0.16 \%$. At $400{ }^{\circ} \mathrm{C}$ and $>60 \mathrm{~min}$, the $A A D$ increased as the residence time increased and tended to reach an equilibrium state. At 420 ${ }^{\circ} \mathrm{C}$ and above, all $A A D$ values were above the uncertainty range and increased as temperature or residence time or both increased. These results agree well with visual observations.

Fig. 7 plots the mean GC retention time $(\bar{\tau})$ versus the thermal stressing residence time at varying temperatures. At $300{ }^{\circ} \mathrm{C}, \bar{\tau}$ slightly increased when DF was thermally stressed for $600 \mathrm{~min}$, At $400{ }^{\circ} \mathrm{C}, \bar{\tau}$ remained nearly constant within $60 \mathrm{~min}$ and then decreased when the residence time increased to $180 \mathrm{~min}$, which agrees with the $A A D \%$ changes presented in Fig. 6. When the residence time increased from $180 \mathrm{~min}$ to $300 \mathrm{~min}$ and further to $600 \mathrm{~min}, \bar{\tau}$ remained constant initially and then slightly increased. These results suggest that longer residence time favors polymerization reactions to form higher molecular weight compounds. At $420{ }^{\circ} \mathrm{C}$ and above, $\bar{\tau}$ decreased as temperature or residence time (up to $120 \mathrm{~min}$ ) or both increased. 
Finally, a small temperature-time window (400-420 $\left.{ }^{\circ} \mathrm{C}, 0-60 \mathrm{~min}\right)$ was determined where DF showed very good stability. Above this window, DF decomposition would become an issue. Decomposition would change fuel chemical and physical properties, further affect spray and combustion behavior, and ultimately, influence emissions and energy efficiency. In the worst scenario, decomposition would cause significant engine failure [4]. DF will remain in the liquid state at $400-420{ }^{\circ} \mathrm{C}$ because the critical temperature of $\mathrm{DF}$ is greater than $420{ }^{\circ} \mathrm{C}$, as discussed in Section 3.1. Therefore, to guarantee a supercritical state, phase transition agents would be required to reduce the critical temperature of fuel mixtures to below $420{ }^{\circ} \mathrm{C}$ without or with minimally sacrificing fuel combustion properties. $\mathrm{CO}_{2}$ was proposed as such an agent [1] and the effect on DF stability is evaluated below.

\subsection{Effect of $\mathrm{CO}_{2}$ on DF thermal stability}

Results obtained from the second set of batch thermal stressing experiments (Table 1, run \#18-21) are presented in Fig. 8. Fig. 8A shows that the $A A D$ s for $D F / C_{2}(18-B, 19-B, 20-B$ and 21-B) were greater than those for the corresponding DF samples (18-A, 19-A, 20-A and 21-A), indicating that DF stability reduced with the addition of $\mathrm{CO}_{2}$. As mentioned earlier, fuel decomposition involves not only pyrolysis reactions but polymerization reactions, and it is well known that aromatic and heteroaromatic compounds are significantly involved in deposit formation [16]. Therefore, some precursors for the formation of polycyclic aromatics hydrocarbons (PAHs) were examined. Fig. 8B-E shows that $A \%$ of four aromatic compounds including naphthalene, 2methylnaphthalene, 1-methylnaphthalene and 1, 4, 5-trimethylnaphthalene increased with the addition of $\mathrm{CO}_{2}$. These results may lead to the conclusion that $\mathrm{CO}_{2}$ promoted DF decomposition. However, we have overlooked the pressure effect. As noticed in Table 1, the thermal stressing pressures increased with the addition of $\mathrm{CO}_{2}$ by nearly one order of magnitude from 2-6 MPa for 
DF to 30-70 $\mathrm{MPa}$ for $\mathrm{DF} / \mathrm{CO}_{2}$. To eliminate the pressure effect, isobaric continuous flow thermal stressing experiments were conducted at $440{ }^{\circ} \mathrm{C}$ and $30 \mathrm{MPa}$ for a residence time of $30 \mathrm{~min}$, and results are presented in Fig. 9 and discussed below.

The continuous flow systems reached the steady state within 120 min for both runs (run \#23 for $\mathrm{DF}$ and run \#24 for $\mathrm{DF} / \mathrm{CO}_{2}$ in Table 1). The steady state conditions maintained for about 300 min for both runs and thus only samples collected in 120-420 min are included in this discussion. Photos of two sets of DF samples are presented in Fig. 9A, showing slight differences in color changes between two runs. The $A A D$ values and changes in $A \%$ for four PAH precursors are reported in Fig. 9B-F, respectively, and the error bars indicate the standard deviations. Under the isobaric conditions, the $A A D$ value and the concentrations of all four PAH precursors slightly decreased with the addition of $\mathrm{CO}_{2}$. This observation suggests that although $\mathrm{CO}_{2}$ was not able to effectively prevent DF decomposition, it did not promote DF decomposition. This opposite outcome is a strong evidence to support the argument that the enhancement in DF decomposition with the addition of $\mathrm{CO}_{2}$ in the batch experiments was actually caused by the increase in fuel pressure and $\mathrm{CO}_{2}$ itself had a minimal chemical effect on DF decomposition. In addition, it is noticed that the concentration of 1, 4, 5-trimethylnaphthalene decreased after the thermal stressing process regardless of the $\mathrm{CO} 2$ concentration. The possible explanation for this observation is either this chemical decomposes to form smaller molecules or it undergoes polymerization reactions to form higher molecular weight compounds or both. Additional research is required to address this issue.

Fig. 9G plots the pressure drops across the micro-filter for both the $\mathrm{DF}$ and the $\mathrm{DF} / \mathrm{CO}_{2}$ runs. The pressure drop for the $\mathrm{DF} / \mathrm{CO}_{2}$ run was lower than that for the $\mathrm{DF}$ run, which may be explained by the reduction in fuel viscosity with the addition of $\mathrm{CO}_{2}$. During thermal stressing of DF, the pressure drop increased by about $25 \%$ from $0.060 \mathrm{MPa}$ at $120 \mathrm{~min}$ to $0.075 \mathrm{MPa}$ at $420 \mathrm{~min}$, and this increase was mainly caused by the accumulation of solid deposits inside the micro-filter. 
During thermal stressing of the $\mathrm{DF} / \mathrm{CO}_{2}$ mixture, the pressure drop did not increase; instead it slightly decreased from 0.041 to $0.035 \mathrm{MPa}$ within the same thermal stressing duration, despite some variations, which suggests that $\mathrm{CO}_{2}$ was able to effectively prevent accumulation of solid deposits. Since $\mathrm{CO}_{2}$ was not able to prevent DF decomposition as discussed in the preceding paragraph, one possible interpretation for this new phenomenon is the phase transition effect. As discussed in Section 3.1, the addition of $10 \mathrm{wt} \%$ of $\mathrm{CO}_{2}$ brings the critical temperature of the $\mathrm{DF} / \mathrm{CO}_{2}$ mixture down to below $440{ }^{\circ} \mathrm{C}$ and consequently, a phase transition from the liquid state to the supercritical state occurs. Supercritical fluids have unusual high solubilities and therefore possibly minimize deposition on fuel pipe walls [16]. In addition to the solubilization effect, the near-critical or supercritical environment may also promote unique reactions and affect product distributions [29-31].

Finally, it may be concluded that $\mathrm{CO}_{2}$ is not able to prevent DF decomposition, but it can prevent or reduce accumulation of solid deposits inside fuel pipes, which is very encouraging. Also, addition of $\mathrm{CO}_{2}$ can reduce the critical temperature of fuel mixtures and thus, the supercritical fuel delivery and injection system can be operated at lower temperatures compared with using pure DF. However, additional investigations are necessary to address the chemical mechanism involved in the fuel coke reduction by $\mathrm{CO}_{2}$ and the effect of $\mathrm{CO}_{2}$ on spray and combustion behavior.

\subsection{Formation of solid deposits}

Fig. 10 shows SEM images of stainless steel sheets before and after thermal treatment in DF at 300,400 and $440{ }^{\circ} \mathrm{C}$ for 120 to $600 \mathrm{~min}$. These images demonstrate significant morphology changes among different thermal stressing conditions. Ring-type deposits (in white) of varying ring diameter up to $3 \mu \mathrm{m}$ were formed when DF was stressed at $300{ }^{\circ} \mathrm{C}$ for $600 \mathrm{~min}$ (Fig. 10B). Similar structures, yet of smaller sizes, were observed at $400{ }^{\circ} \mathrm{C}$ for the same residence time (Fig. 10D). 
Reducing the residence time to $300 \mathrm{~min}$ at $400{ }^{\circ} \mathrm{C}$ resulted in deposits in much smaller size. As temperature increased to $440{ }^{\circ} \mathrm{C}$, a substantial number of deposits were produced (Fig. 10E), and the diameters of these crystal-like structures were in the order of magnitude of $100 \mathrm{~nm}$ with a relatively narrower size distribution (Fig. 10F). The morphology of solid deposits formed at $440{ }^{\circ} \mathrm{C}$ is consistent with that previously reported for the pyrolytic regime at higher temperatures [32]. The different morphologies of solid deposits observed under different thermal stressing conditions may imply different solid deposit formation mechanisms.

It has been suggested that the nature and amount of solid deposition from the thermal decomposition of jet fuel were dependent on the substrate properties and jet fuel composition [33]. It was also reported that stainless steel tubes formed more deposits than aluminum tubes [16] probably due to the catalytic behavior of iron and iron-based alloys during carbon oxidation [33]. Contradictorily, however, a recent study showed that the deposits were formed by reactions in the liquid phase and the surface played a negligible role in deposit formation [34]. Other studies have reported the effects of trace amounts of sulfur and nitrogen compounds and other contaminants such as metals $[35,36]$, because these elements were found in large concentrations in deposits compared to fresh fuels [25]. A recent study reported that nitrogen and sulfur compounds were presented only in the liquid-phase product, but not in the solid phase deposits, and indicated that they did not aggregate during solid formation [34]. Despite a number of studies on addressing the science behind solid deposit formation, the nature and the mechanism are still far from understood. These studies are beyond the scope of this work. Further studies are definitely required to address these issues and would contribute to the development of strategies for preventing DF coking.

\section{Conclusions}

In this work, the thermal stability of DF under subcritical and supercritical conditions was 
experimentally evaluated in both batch and continuous flow thermal stressing systems. The effects of temperature, thermal stressing duration and $\mathrm{CO}_{2}$ on $\mathrm{DF}$ stability and decomposition were examined. $\mathrm{CO}_{2}$ was examined as a potential diluent to reduce the DF critical temperature and to determine whether it prevents DF coking at high temperatures. It was found that the thermal stability of DF reduced as temperature or thermal stressing duration or both increased. The onset temperature of instantaneous decomposition was about $470{ }^{\circ} \mathrm{C} . \mathrm{CO}_{2}$ was not able to prevent DF decomposition, but it could prevent or reduce accumulation of solid deposits inside fuel pipes mainly due to the effect on the solubilization capacity of DF. Finally, two different structures and morphologies of solid deposits were observed under different batch thermal stressing conditions and might imply varying deposition mechanisms. The significance of this study is that it provides a deeper insight of thermal stability and decomposition behavior of DF and determines a temperaturetime window where supercritical DF combustion in diesel engines may work.

\section{Acknowledgements}

We gratefully acknowledge the New York State Energy Research and Development Authority (NYSERDA) for the financial support (Agreement \# 8915-1-2). We thank Dr. Xinzhu Gu for helping with the SEM experiments and thank Mr. Jiuxu Liu for helping with the PRO/II simulation.

\section{References}

[1] L.L. Tavlarides, G. Anitescu, Supercritical diesel fuel composition, combustion process, and fuel system, US Patent No. 7,488,357 547 (2009).

[2] G. Anitescu, R. Lin, L.L. Tavlarides, Preparation, injection and combustion of supercritical fluids, in: Directions in Engine-Efficiency and Emissions Research (DEER) Conference, Dearborn, 
MI, August, 2009.

[3] R. Lin, Issues on clean diesel combustion technology using supercritical fluids: thermophysical properties and thermal stability of diesel fuel, $\mathrm{PhD}$ Dissertation, Syracuse University, Syracuse, 2011.

[4] D.H. Scharnweber, Hypergolic combustion demonstration in a reciprocating internal combustion engine, Technical Report No. 13,042, U.S. Army TACOM R\&D Center, Warren, MI, 1984. [5] J.D. Bacha, D.G. Lesnini, Diesel fuel thermal stability at $300{ }^{\circ} F$, in: Proceedings of the $6^{\text {th }}$ International Conference on Stability and Handling of Liquid Fuels, Vancouver, Canada, 1997, pp. 671-684.

[6] Z.D. Kalitchin, S.K. Ivanov, M.I. Boneva, A. Ivanov, K. Kanariev, P.T. Georgiev, S.K. Tanielyan, Thermo-chemical and thermo-oxidative stability of diesel fuels containing components of light catalytic gas oil, in: Proceedings of the $6^{\text {th }}$ International Conference on Stability and Handling of Liquid Fuels, Vancouver, Canada, 1997, pp. 685-697.

[7] S.D. Schwab, T.J. Henly, J.F. Moxley, K.T. Miller, Thermal stability of diesel fuel, in: Proceedings of the $7^{\text {th }}$ International Conference on Stability and Handling of Liquid Fuels, Graz, Austria, 2000, pp. 13-32.

[8] R. Banavali, B. Chheda, Improvement of thermal stability of diesel fuel using tertiary alkyl primary amines, in: Proceedings of the $7^{\text {th }}$ International Conference on Stability and Handling of Liquid Fuels, Graz, Austria, 2000, pp. 85-109.

[9] L.L. Stavinoha, J.G. Barbee, D.M. Yost, Thermal Oxidation Stability of Diesel Fuels, Interim Report, 1986. (http://www.dtic.mil/cgibin/GetTRDoc?Location=U2\&doc=GetTRDoc.pdf\&AD=ADA173850) [10] D. Nickolaus, A.H. Lefebvre, Fuel thermal stability effects on spray characteristics, J. Propulsion and Power 3 (1987) 502-507. 
[11] E.J. Beal, D.R. Hardy, Thermal stability of diesel fuels by quantitative gravimetric JFTOT, Preprints - American Chemical Society. Division of Petroleum Chemistry. 39 (1994) 958-961.

[12] G. Anitescu, L.L. Tavlarides, D. Geana, Phase transitions and thermal behavior of fuel/diluent mixtures, Energy and Fuels 23 (2009) 3068-3077.

[13] B.D. Batts, A.Z. Fathoni, A literature review on fuel stability studies with particular emphasis on diesel oil, Energy and Fuels 5 (1991) 2-21.

[14] B. Beaver, L. Gao, C. Burgess-Clifford, M. Sobkowiak, On the mechanisms of formation of thermal oxidative deposits in jet fuels. Are unified mechanisms possible for both storage and thermal oxidative deposit formation for middle distillate fuels? Energy and Fuels 19 (2005) 15741579.

[15] J. Chin, A. Lefebvre, Experimental study on hydrocarbon fuel thermal stability, J. Thermal Science 1 (1992) 70-74.

[16] R.N. Hazlett, Physicochemical aspects of aviation fuel thermal stability, in: P.W. Kirklin, P. David (Eds.), Aviation Fuel: Thermal Stability Requirements, ASTM, Philadelphia, PA, 1992, pp. $18-33$.

[17] W.F. Taylor, Deposit formation from deoxygenated hydrocarbons. I. general features, Product R\&D. 13 (1974) 133-138.

[18] G. Anitescu, Supercritical fluid technology applied to the production and combustion of diesel and biodiesel fuels, PhD Dissertation, Syracuse University, Syracuse, 2008.

[19] R. Lin, L.L. Tavlarides, Diffusion coefficients of diesel fuel and surrogate compounds in supercritical carbon dioxide, J. Supercritical Fluids 52 (2010) 47-55.

[20] R. Lin, L.L. Tavlarides, Thermophysical properties needed for the development of the supercritical diesel combustion technology: Evaluation of diesel fuel surrogate models, J. Supercritical Fluids 71 (2012) 136-146. 
[21] R. Lin, Y. Zhu, L.L. Tavlarides, Mechanism and kinetics of thermal decomposition of biodiesel fuel, Fuel (2012), http://dx.doi.org/10.1016/j.fuel.2012.12.013.

[22] T. Edwards, P.D. Liberio, The relationship between oxidation and pyrolysis in fuels heated to $\sim 590{ }^{\circ} \mathrm{C}\left(1100{ }^{\circ} \mathrm{F}\right)$, Preprints - American Chemical Society. Division of Petroleum Chemistry. 39 (1994) 92-96.

[23] J.S. Ervin, T.F. Williams, G. Hartman, Effect of test period on the rate of fouling in a complex flowing system: Structure of jet fuels V, Preprints - American Chemical Society. Division of Petroleum Chemistry 43 (1998) 373-377.

[24] J.F. Stewart, Supercritical pyrolysis of the endothermic fuels methylcyclohexane, decalin, and tetralin, PhD Dissertation, Princeton University, 1999.

[25] R.N. Hazlett, Thermal Oxidation Stability of Aviation Turbine Fuels, ASTM, Philadelphia, PA, 1991.

[26] G. Soave, Equilibrium constants from a modified Redlich-Kwong equation of state, Chemical Engineering Science 27 (1972) 1197-1203.

[27] B.A. Stradi, J.F. Brennecke, J.P. Kohn, Reliable computation of mixture critical points, AIChE J. 47 (2001) 212-221.

[28] B.E. Poling, J.M. Prausnitz, J.P. O’Connell, The Properties of Gases and Liquids, 5th ed., McGraw-Hill, New York, 2001.

[29] J. Yu, S. Eser, Thermal decomposition of C10-C14 normal alkanes in near-critical and supercritical regions: product distributions and reaction mechanisms, Industrial and Engineering Chemistry Research 36 (1997) 574-584.

[30] J. Yu, S. Eser, Kinetics of supercritical-phase thermal decomposition of C10-C14 normal alkanes and their mixtures, Industrial and Engineering Chemistry Research 36 (1997) 585-591. [31] M.L. Somers, J.W. McClaine, M.J. Wornat, The formation of polycyclic aromatic 
hydrocarbons from the supercritical pyrolysis of 1-methylnaphthalene, Proceedings of the Combustion Institute 31 (2007) 501-509.

[32] M.J. DeWitt, T. Edwards, L. Shafer, D. Brooks, R. Striebich, S.P. Bagley, M.J. Wornat, Effect of aviation fuel type on pyrolytic reactivity and deposition propensity under supercritical conditions, Industrial and Engineering Chemistry Research 50 (2011) 10434-10451.

[33] S. Eser, R. Venkataraman, O. Altin, Deposition of carbonaceous solids on different substrates from thermal stressing of JP-8 and jet A fuels, Industrial and Engineering Chemistry Research 45 (2006) 8946-8955.

[34] R. Venkataraman, S. Eser, Characterization of deposits formed on diesel injectors in field test and from thermal oxidative degradation of n-hexadecane in a laboratory reactor, Chemistry Central J. 2 (2008) 25-35.

[35] Ö. Gül, L.R. Rudnick, H.H. Schobert, The effect of chemical composition of coal-based jet fuels on the deposit tendency and morphology, Energy and Fuels 20 (2006) 2478-2485.

[36] C. Song, S. Eser, H.H. Schobert, P.G. Hatcher, Pyrolytic degradation studies of a coal-derived and a petroleum-derived aviation jet fuel, Energy and Fuels 7 (1993) 234-243. 

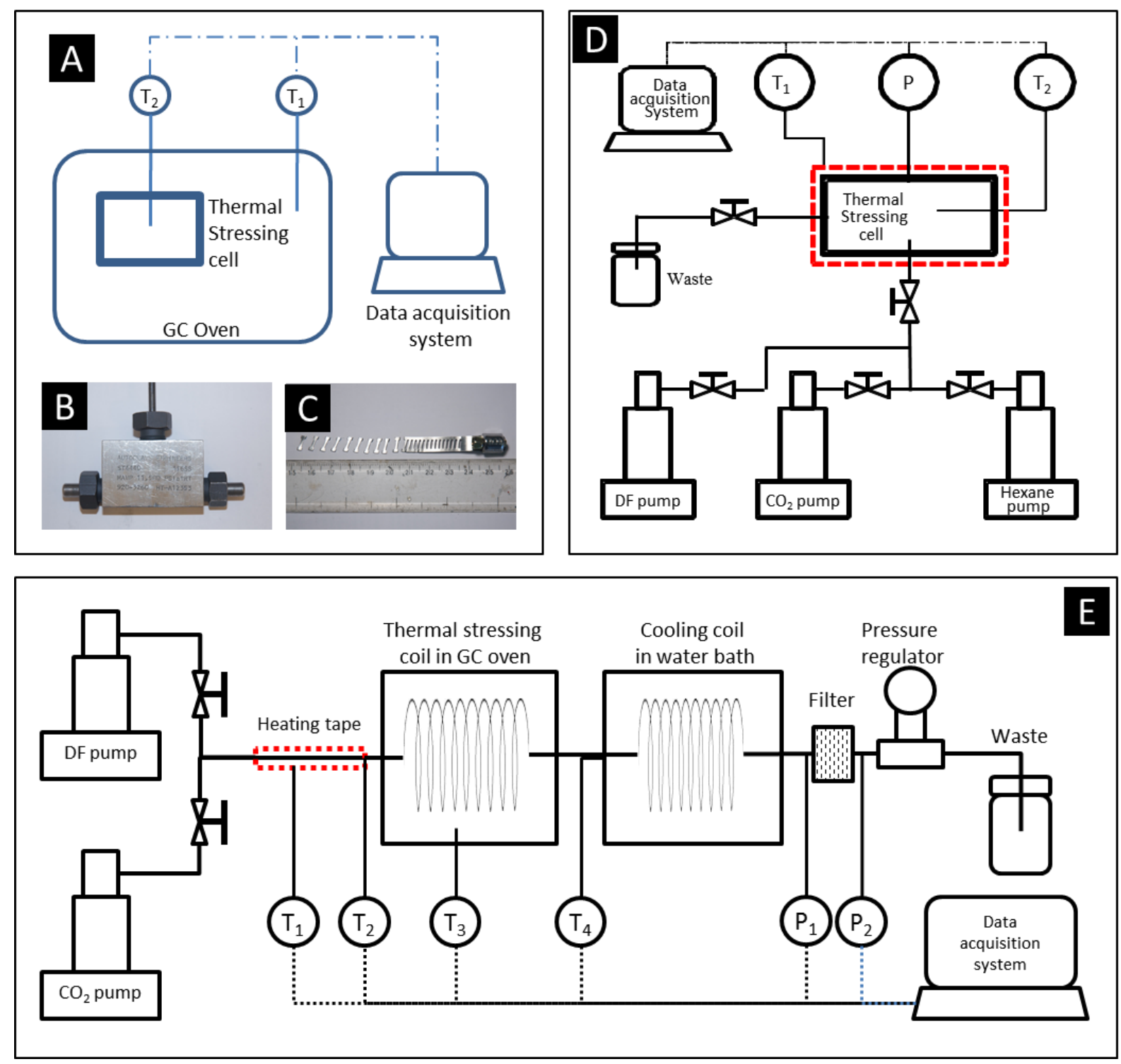

Fig. 1 Schematic diagrams of the experimental setups. A: batch setup for thermal stressing of diesel fuel; B: photograph of the stainless steel tee; C: photograph of stainless steel sheets used to capture solid deposits; D: batch setup for thermal stressing of diesel fuel- $\mathrm{CO}_{2}$ mixtures; $\mathrm{E}$ : continuous flow thermal stressing system. 

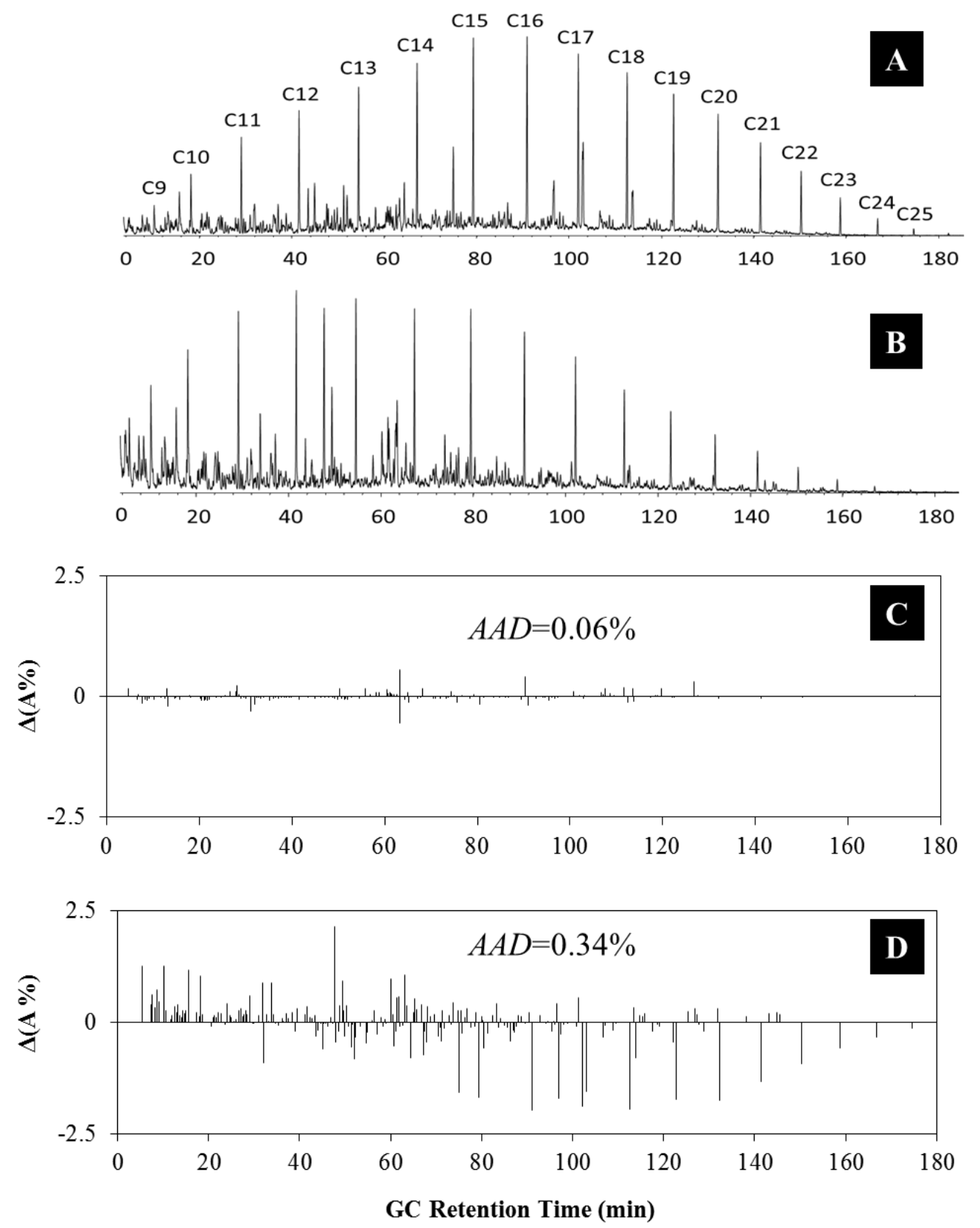

Fig. 2 Example of GC-MS chromatograms and quantitative analysis. A: chromatogram of fresh diesel fuel; B: chromatogram of diesel fuel thermally stressed at $440{ }^{\circ} \mathrm{C}$ for $120 \mathrm{~min}$; C: typical peak area percentage variation between two GC-MS measurements for fresh diesel fuel; D: peak area percentage changes between chromatograms A and B; C9-C25 indicate normal alkanes having carbon numbers from 9 to 25 . 


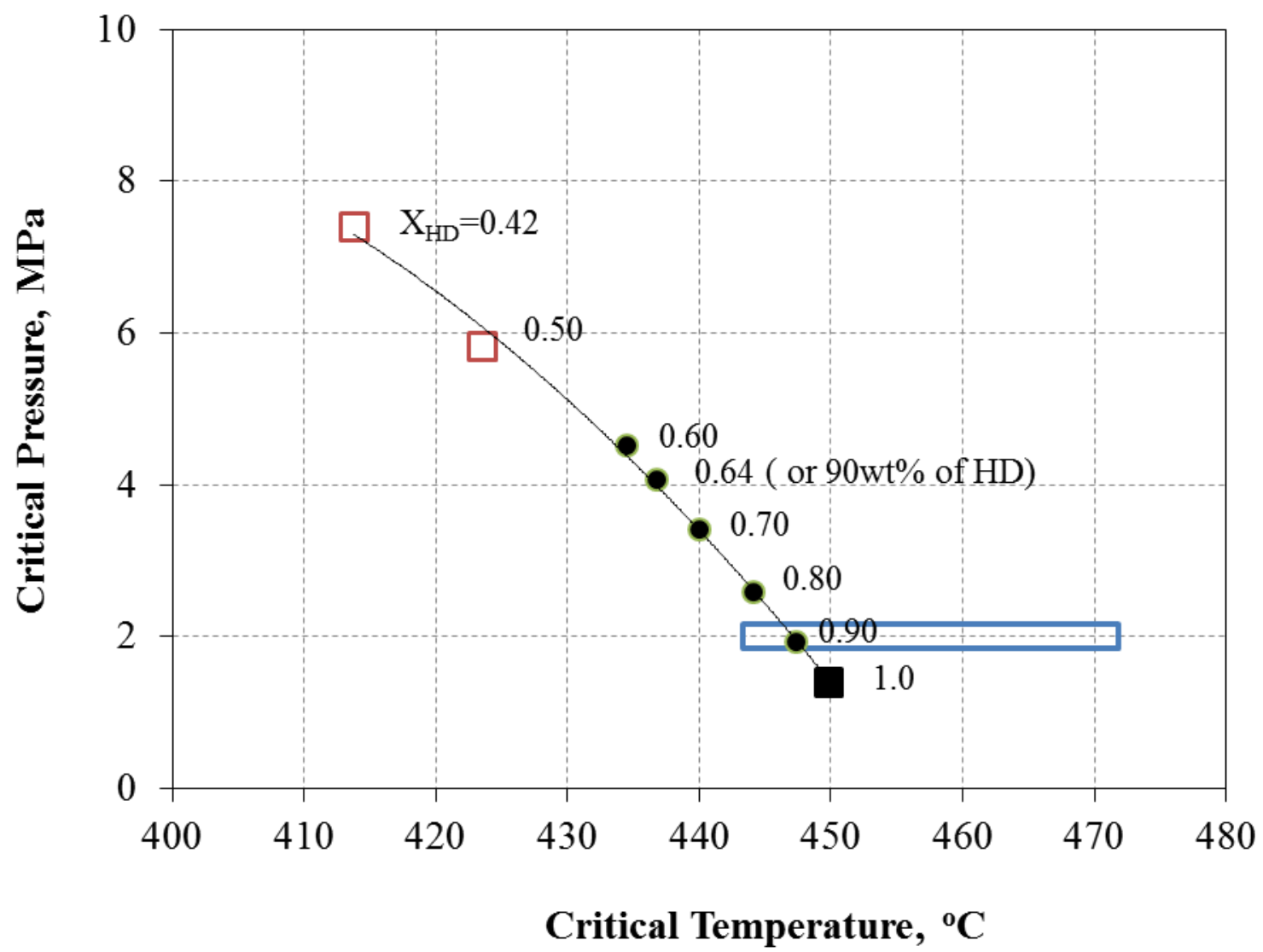

Fig. 3 Estimated critical points of diesel fuel and diesel fuel surrogate (n-hexadecane)- $\mathrm{CO}_{2}$ mixtures. $\mathrm{X}_{\mathrm{HD}}$ : molar fraction of n-hexadecane; $(\square)$ data from Ref. [24]; ( $\left.\mathbf{\square}\right)$ critical point of n-hexadecane from Ref. [25]; (-) estimated in this work; solid line: critical point trend line; rectangle: critical point range of real diesel fuel [17]. 


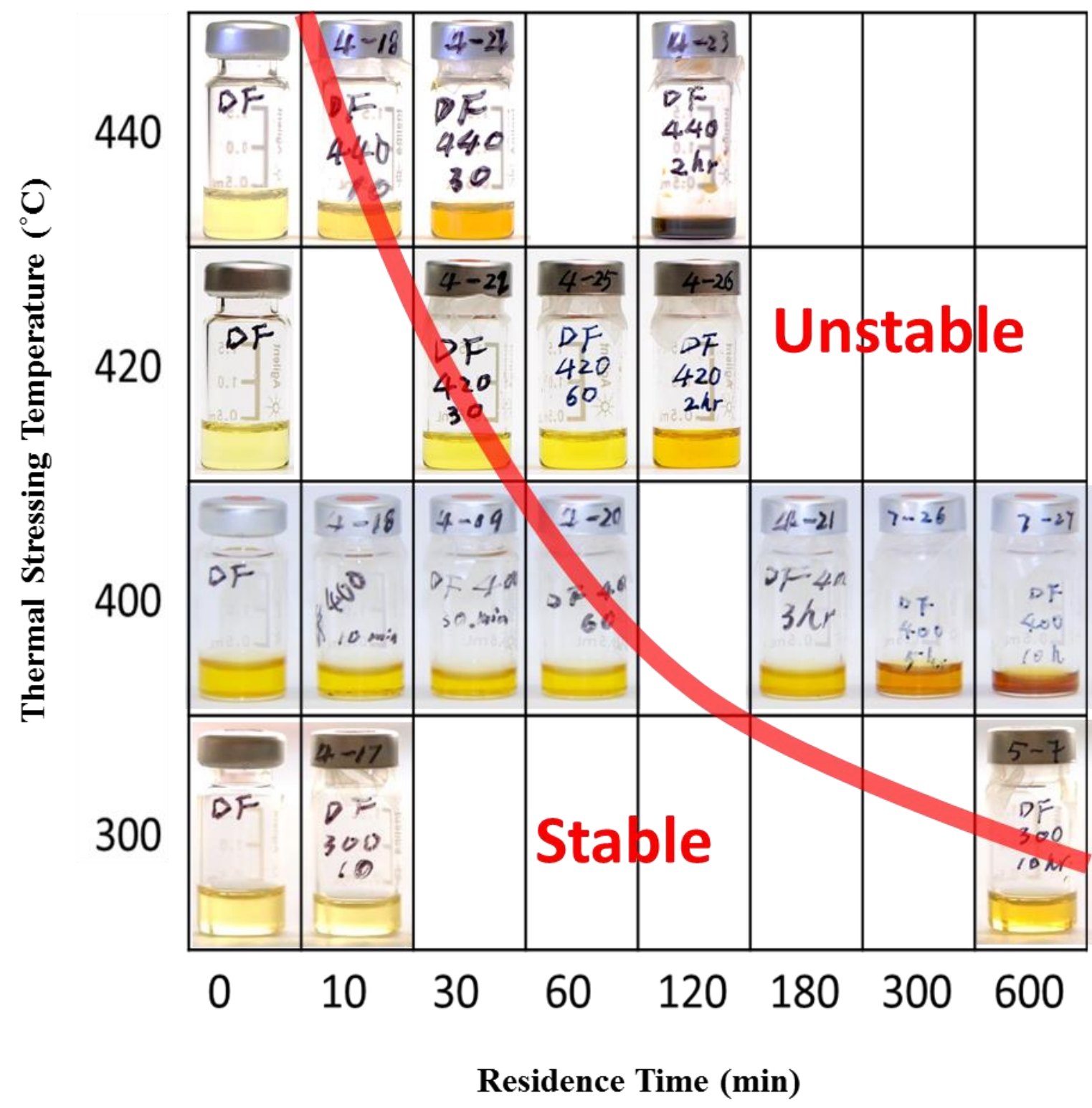

Fig. 4 Selected photos of diesel fuel samples collected in the batch thermal stressing experiments. 


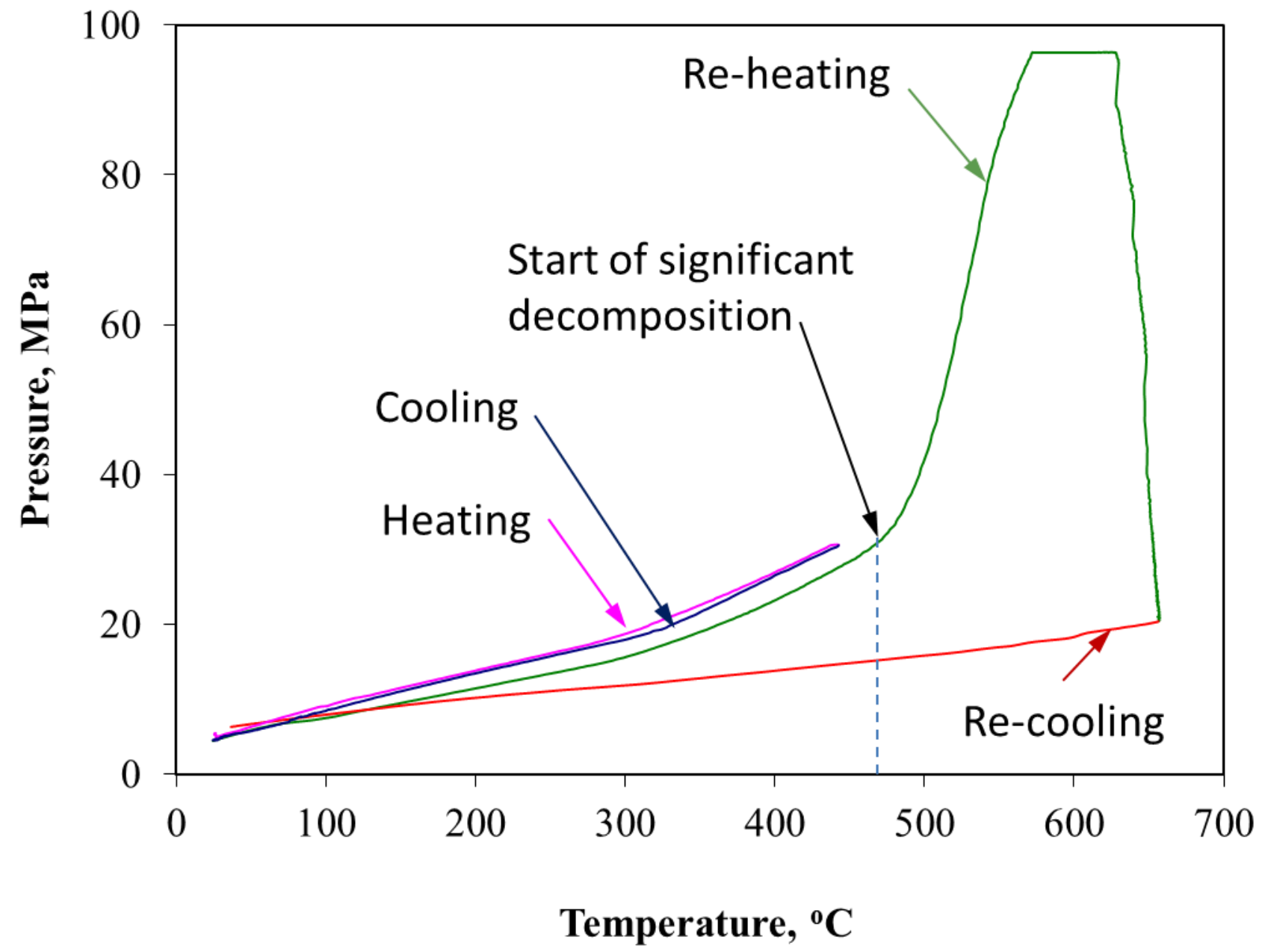

Fig. 5 T-P history for batch thermal stressing of a $\mathrm{DF} / \mathrm{CO}_{2}$ mixture (run \#22 in Table 1) showing the start of significant DF decomposition. 


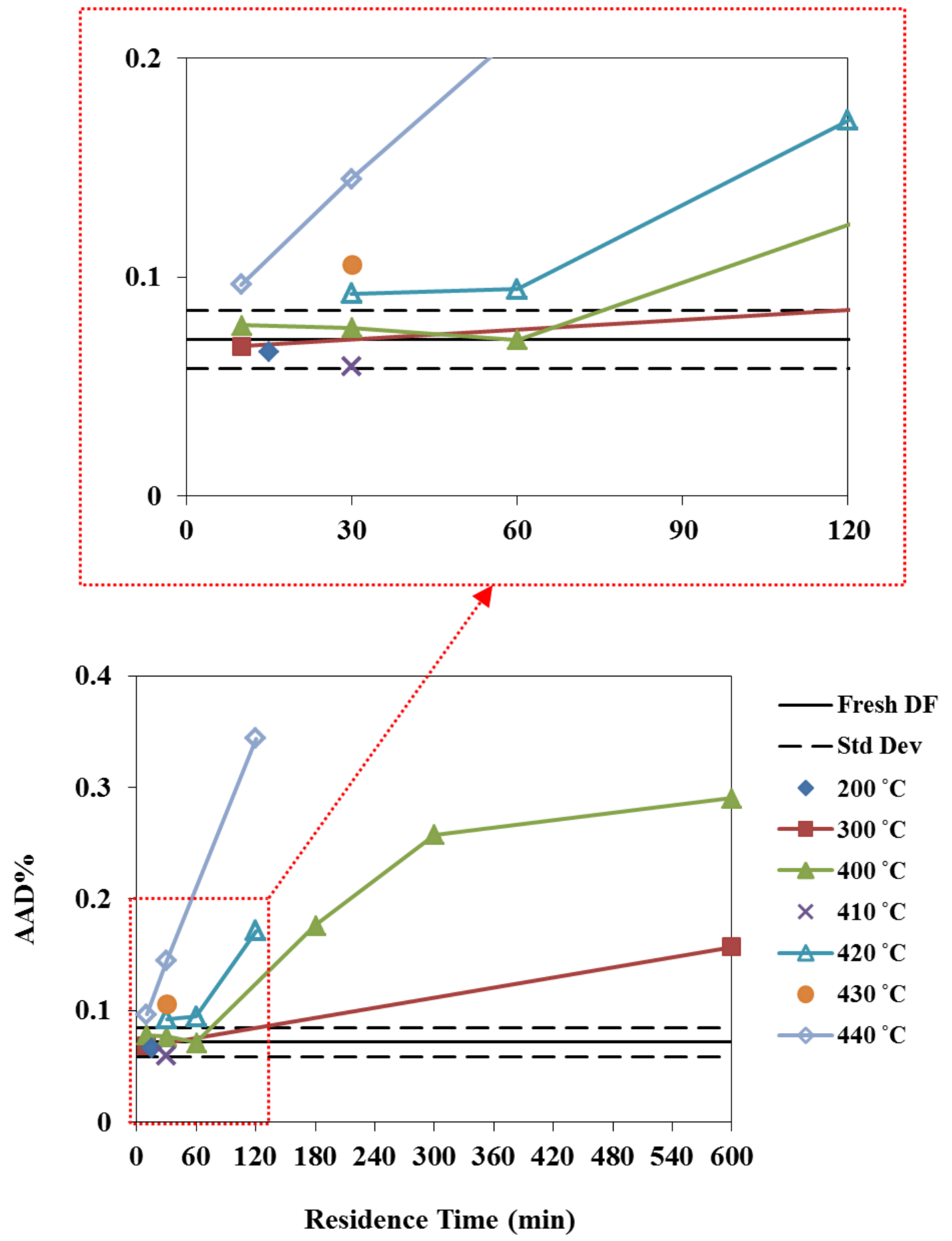

Fig. 6 Quantitative analysis of GC-MS chromatograms showing diesel fuel decomposition under varying batch thermal stressing conditions. 


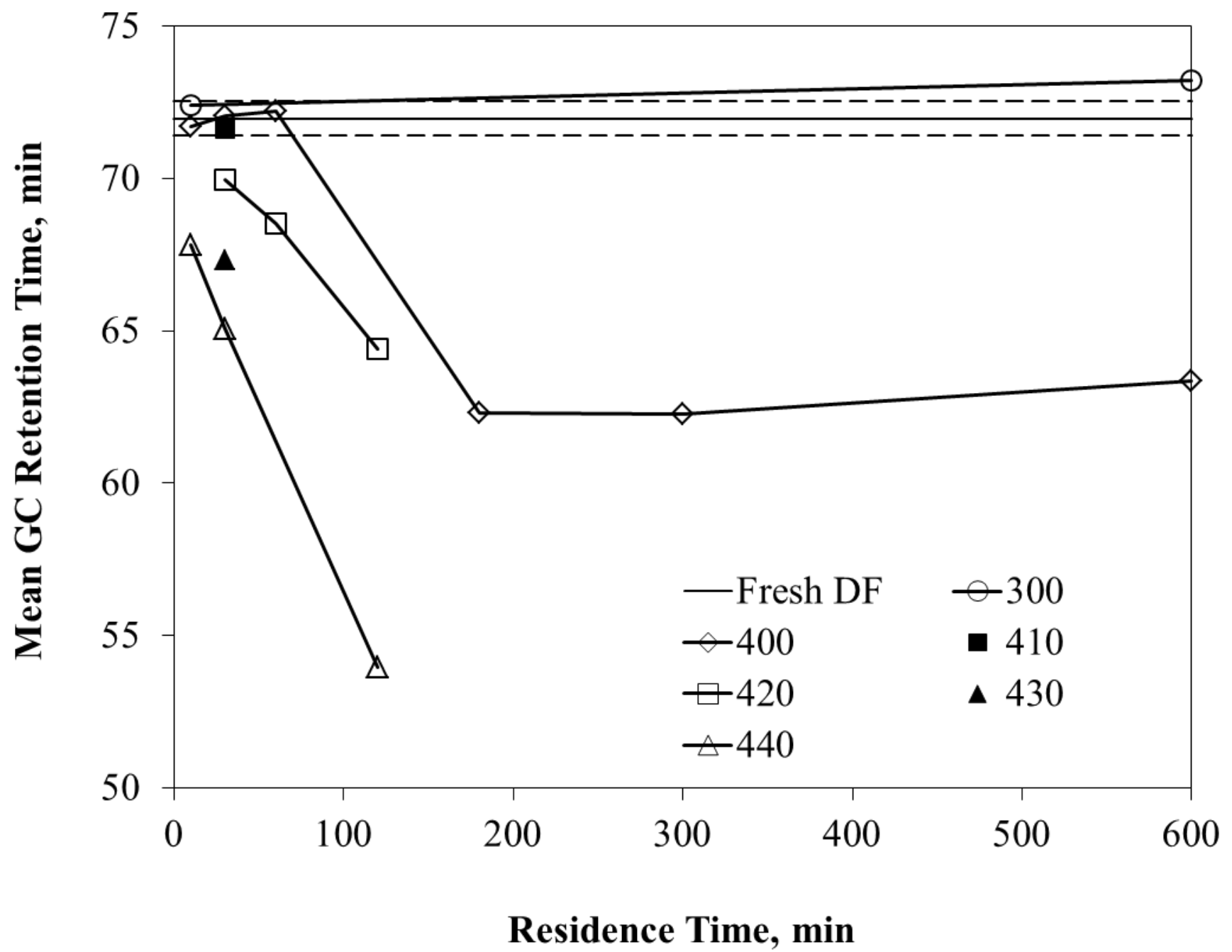

Fig. 7 Changes in mean GC retention time of DF thermally stressed at $300-440{ }^{\circ} \mathrm{C}$ for $10-600 \mathrm{~min}$. The horizontal solid line is for fresh DF and the horizontal dash lines indicate one standard deviation. 

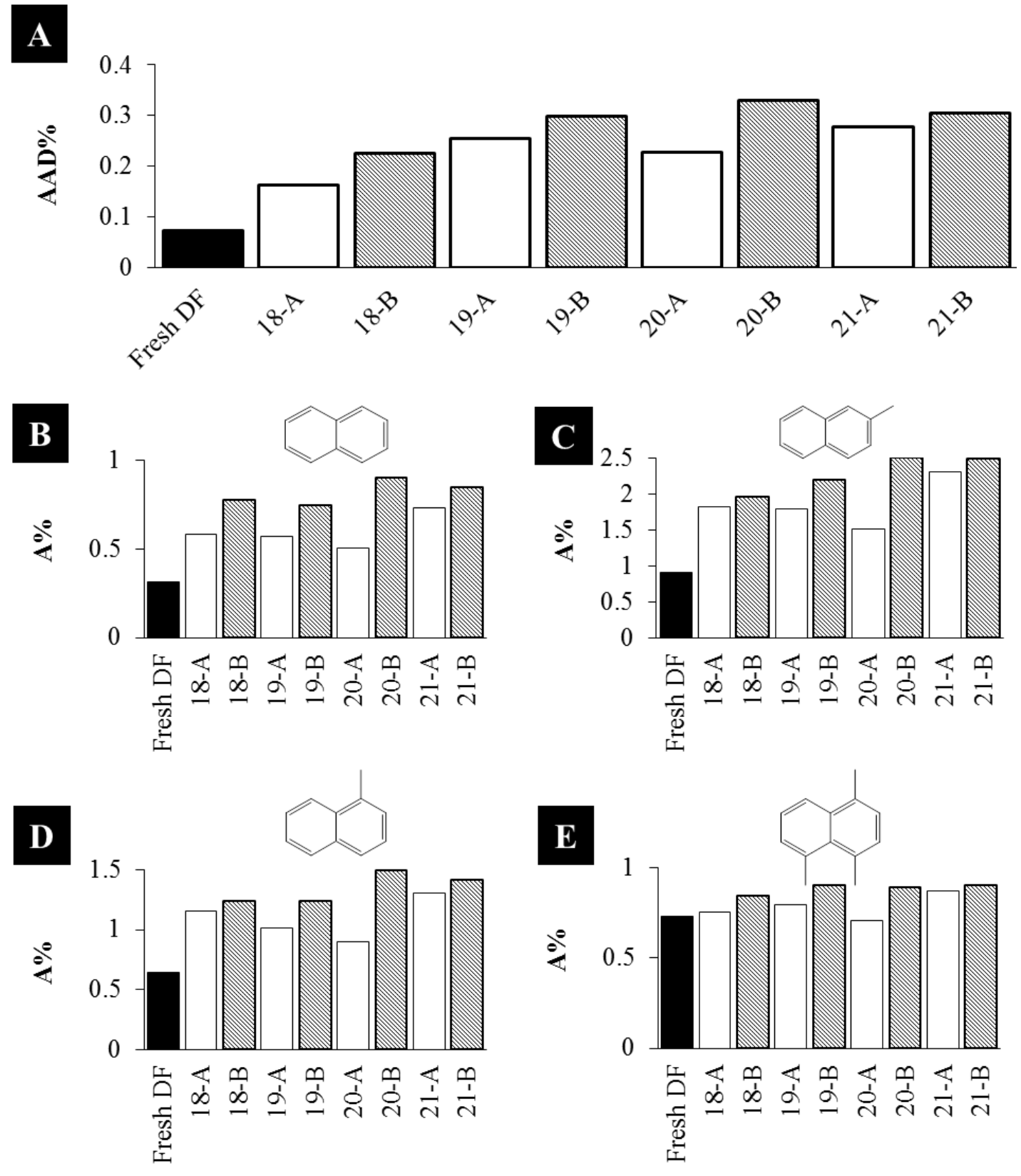

$\begin{array}{lll}\text { Fresh DF } \square \mathrm{DF} & \square \mathrm{DF} / \mathrm{CO}_{2}\end{array}$

Fig. 8 Average absolute deviation of peak area percentages (A) and percentage change for individual peaks (B-E) indicating the effect of $\mathrm{CO}_{2}$ on diesel fuel decomposition. $\mathrm{B}$ : naphthalene (retention time in min: 33.78); C: 2-methylnaphthalene (47.58); D: 1methylnaphthalene (49.27); E: 1, 4, 5-trimethylnaphthalene (73.70). 

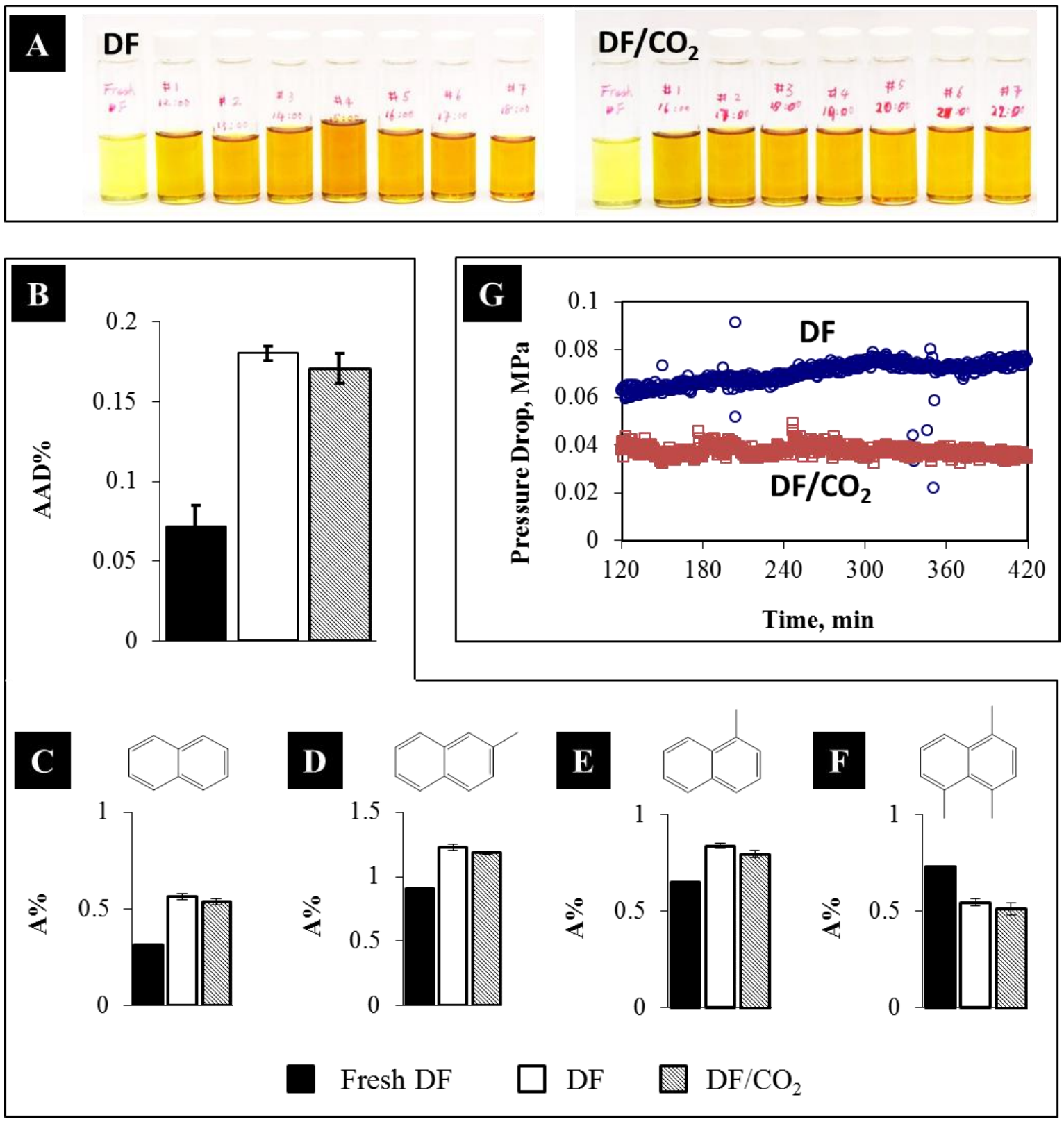

Fig. 9 Results for the continuous flow thermal stressing experiments. A: photos of diesel fuel samples collected during thermal stressing of diesel fuel (DF) and diesel fuel- $\mathrm{CO}_{2}$ mixtures $\left(\mathrm{DF} / \mathrm{CO}_{2}\right)$; B: comparison of the average absolute deviation of peak area percentages; $\mathrm{C}-\mathrm{F}$ : percentage changes for individual peaks for naphthalene (C), 2-methylnaphthalene (D), 1methylnaphthalene (E) and 1, 4, 5-trimethylnaphthalene (F); G: comparison of pressure drop changes. 

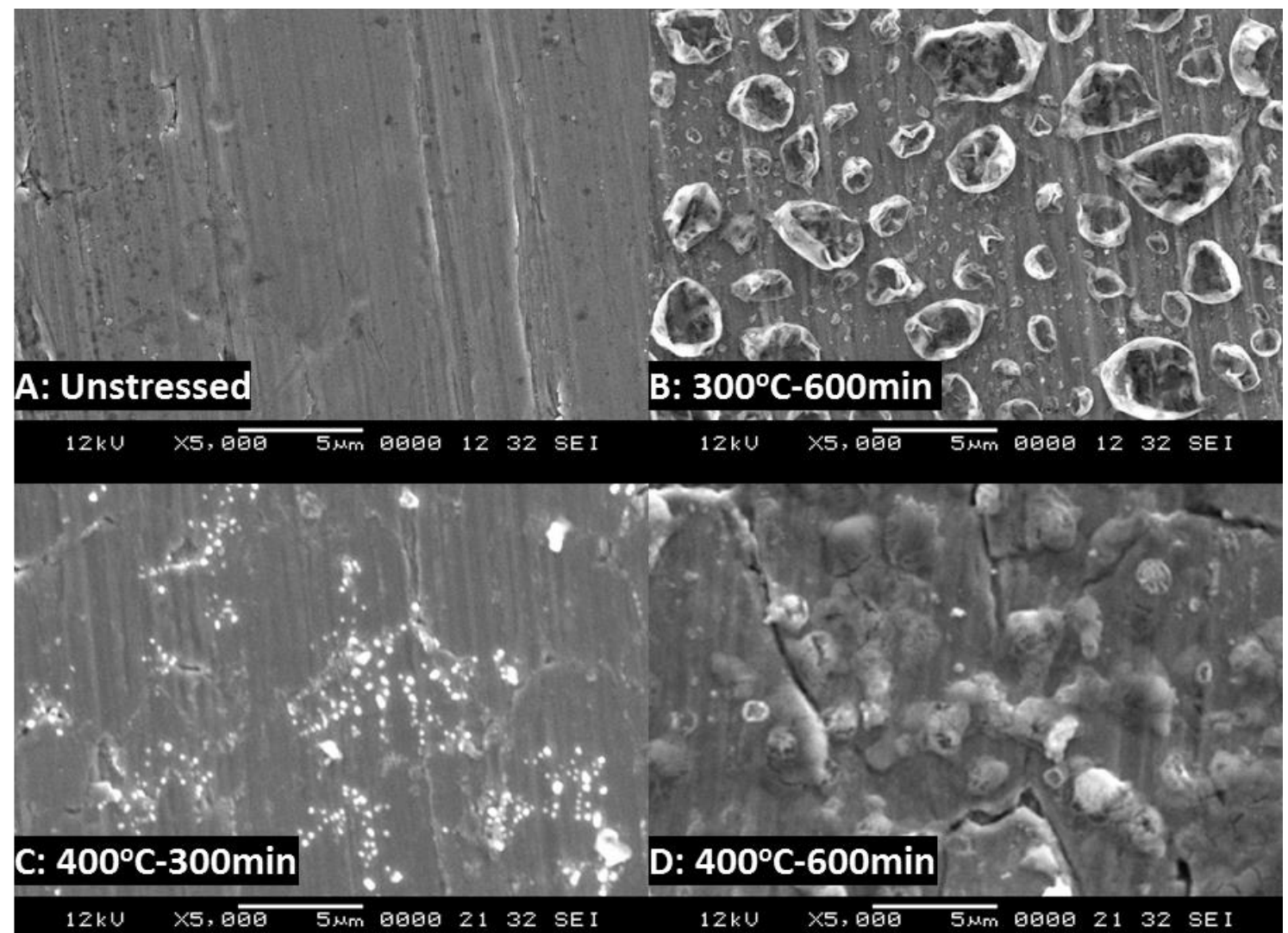

$12 \mathrm{kU} \times 5,0 \overline{60 \quad 5 \mu \mathrm{m}}$ घ96日 2132 SEI

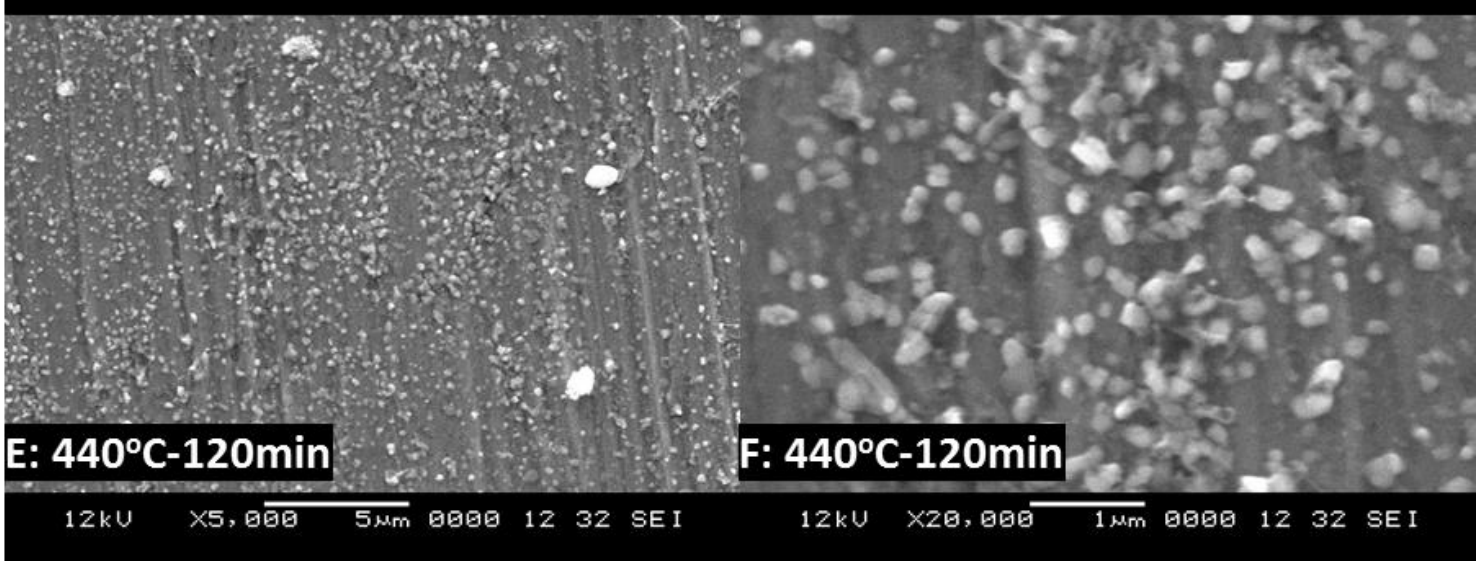

Fig. 10 Selected SEM photographs of solid deposits formed during batch thermal stressing of diesel fuel. $\mathrm{E}$ and $\mathrm{F}$ are for the same sample but were taken using different magnifications as indicated in the photographs. 
Table 1 Experimental conditions for batch thermal stressing of diesel fuel

\begin{tabular}{|c|c|c|c|c|c|c|c|}
\hline Exp. & Run\# & $\mathrm{T}\left({ }^{\circ} \mathrm{C}\right)$ & $\tau(\min )$ & $\overline{\mathrm{DF}}(\mathrm{ml})$ & $\mathrm{CO}_{2}(\mathrm{MPa})^{\mathrm{a}}$ & $\mathrm{P}(\mathrm{MPa})$ & Phase $^{c}$ \\
\hline \multirow{17}{*}{ Batch-DF } & 1 & 200 & 15 & 0.45 & 0 & $\mathrm{n} / \mathrm{a}$ & $\mathrm{L}$ \\
\hline & 2 & 300 & 10 & 0.45 & 0 & $\mathrm{n} / \mathrm{a}$ & $\mathrm{L}$ \\
\hline & 3 & 300 & 600 & 0.45 & 0 & $\mathrm{n} / \mathrm{a}$ & $\mathrm{L}$ \\
\hline & 4 & 400 & 10 & 0.45 & 0 & $\mathrm{n} / \mathrm{a}$ & $\mathrm{L}$ \\
\hline & 5 & 400 & 30 & 0.45 & 0 & $\mathrm{n} / \mathrm{a}$ & $\mathrm{L}$ \\
\hline & 6 & 400 & 60 & 0.45 & 0 & $\mathrm{n} / \mathrm{a}$ & $\mathrm{L}$ \\
\hline & 7 & 400 & 180 & 0.45 & 0 & $\mathrm{n} / \mathrm{a}$ & $\mathrm{L}$ \\
\hline & 8 & 400 & 300 & 0.45 & 0 & $\mathrm{n} / \mathrm{a}$ & $\mathrm{L}$ \\
\hline & 9 & 400 & 600 & 0.45 & 0 & $\mathrm{n} / \mathrm{a}$ & $\mathrm{L}$ \\
\hline & 10 & 410 & 30 & 0.45 & 0 & $\mathrm{n} / \mathrm{a}$ & $\mathrm{L}$ \\
\hline & 11 & 420 & 30 & 0.45 & 0 & $\mathrm{n} / \mathrm{a}$ & $\mathrm{L}$ \\
\hline & 12 & 420 & 60 & 0.45 & 0 & $\mathrm{n} / \mathrm{a}$ & $\mathrm{L}$ \\
\hline & 13 & 420 & 120 & 0.45 & 0 & $\mathrm{n} / \mathrm{a}$ & $\mathrm{L}$ \\
\hline & 14 & 430 & 30 & 0.45 & 0 & $\mathrm{n} / \mathrm{a}$ & $\mathrm{L}$ \\
\hline & 15 & 440 & 10 & 0.45 & 0 & $\mathrm{n} / \mathrm{a}$ & $\mathrm{L}$ \\
\hline & 16 & 440 & 30 & 0.45 & 0 & $\mathrm{n} / \mathrm{a}$ & $\mathrm{L}$ \\
\hline & 17 & 440 & 120 & 0.45 & 0 & $\mathrm{n} / \mathrm{a}$ & $\mathrm{L}$ \\
\hline Batch- & 18-A & 440 & 30 & 1.7 & 0 & $1.8-4.0$ & $\mathrm{~L}$ \\
\hline \multirow{8}{*}{$\mathrm{DF} / \mathrm{CO}_{2}$} & $18-\mathrm{B}$ & 440 & 30 & 1.7 & 4.83 & $29.5-35.3$ & $\mathrm{SC}$ \\
\hline & $19-\mathrm{A}$ & 440 & 45 & 1.2 & 0 & $1.8-4.0$ & $\mathrm{~L}$ \\
\hline & $19-\mathrm{B}$ & 440 & 45 & 1.2 & 4.83 & 29.3-31.6 & $\mathrm{SC}$ \\
\hline & $20-\mathrm{A}$ & 440 & 45 & 1.4 & 0 & $1.7-3.6$ & $\mathrm{~L}$ \\
\hline & $20-B$ & 440 & 45 & 1.4 & 4.83 & $31.1-37.9$ & $\mathrm{SC}$ \\
\hline & $21-\mathrm{A}$ & 440 & 45 & 1.6 & 0 & $2.1-6.4$ & $\mathrm{~L}$ \\
\hline & 21-B & 440 & 45 & 1.6 & 4.83 & $57.0-67.5$ & $\mathrm{SC}$ \\
\hline & 22 & $>600$ & $\mathrm{n} / \mathrm{a}$ & 1.0 & 4.83 & $>90$ & $\mathrm{SC}$ \\
\hline \multirow{2}{*}{ Continuous } & 23 & 440 & 30 & $100^{b}$ & $0^{\mathrm{b}}$ & 30 & $\mathrm{~L}$ \\
\hline & 24 & 440 & 30 & $90^{\mathrm{b}}$ & $10^{\mathrm{b}}$ & 30 & $\mathrm{SC}$ \\
\hline
\end{tabular}

a " 0 " indicates no $\mathrm{CO}_{2}$ added; "4.83" was the initial pressure after loading DF and pressurizing with the system with $\mathrm{CO}_{2}$ at the room temperature.

${ }^{b}$ The unit of these values is weight percent (wt\%).

${ }^{\mathrm{c}}$ L-liquid; SC-supercritical 